\title{
On the Silica Surface Modification and Its Effect on Charge Trapping and Transport in PP-Based Dielectric Nanocomposites
}

\author{
Amirhossein Mahtabani, Ilkka Rytöluoto, Rafal Anyszka, Xiaozhen He, Eetta Saarimäki, Kari Lahti,
} Mika Paajanen, Wilma Dierkes,* and Anke Blume

Cite This: ACS Appl. Polym. Mater. 2020, 2, 3148-3160

Read Online

\section{ACCESS \\ Џlll Metrics \& More \\ Article Recommendations \\ Supporting Information}

ABSTRACT: The effect of filler surface functionalization with 3-aminopropyltriethoxysilane (APTES) on the charge trapping and transport was studied in polypropylene (PP)/(ethylene-octene) copolymer (EOC)/silica nanodielectrics. Different reaction conditions were utilized for silica functionalization to alter the deposited layer morphology. This approach made it possible to engineer the filler-polymer interface to achieve optimized dielectric properties for the nanocomposites. The successful chemical modification of the silica surface was confirmed via thermogravimetric analysis (TGA), Fourier-transform infrared spectroscopy (FTIR),

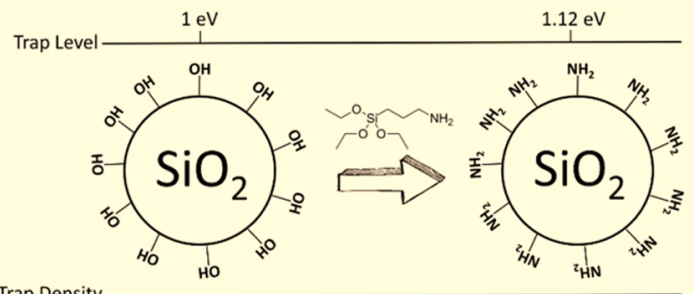

$3 \mathrm{~m}^{-3} \mathrm{eV}^{-1}$ $1.2 \mathrm{~m}^{-3} \mathrm{eV}^{-1}$ and X-ray photoelectron spectroscopy (XPS). Subsequently, the effect of the engineered filler-polymer interface on the nanocomposites' crystallinity was analyzed with differential scanning calorimetry (DSC). Scanning electron microscopy (SEM) was utilized to observe the morphology of the nanocomposite as well as the silica dispersion. Finally, the effect of the silica functionalization on the dielectric properties of $\mathrm{PP} / \mathrm{EOC} /$ silica nanocomposites was tested via thermally stimulated depolarization current (TSDC) and broadband dielectric spectroscopy (BDS). The results suggested that the presence of the amine functionality on the silica reduces interfacial losses in nanocomposites, and hinders further injection of space charge by introducing deep trap states at the filler-polymer interface. Under certain conditions, APTES can form an "island-like" morphology on the silica surface. These islands can facilitate nucleation, inducing transcrystallization at the filler-polymer interface. The island-like structures present on the silica would further contribute to the induction of deep traps at the filler-polymer interface resulting in the reduction of space charge injection.

KEYWORDS: silica surface modification, PP-based nanodielectrics, space charge, dielectric properties, TSDC, HVDC

\section{INTRODUCTION}

The incorporation of nanoparticles in dielectric materials to enhance their insulating properties has been studied extensively in the recent years. ${ }^{1-4}$ Nanomposites containing various fillers, including semiconducting $\left(\mathrm{ZnO}^{5}\right.$ and $\left.\mathrm{TiO}_{2}{ }^{6}\right)$ and insulating particles $\left(\mathrm{MgO},{ }^{7} \mathrm{SiO}_{2}{ }^{8}\right)$, have been reported in the literature, exhibiting substantial enhancements in, e.g., dielectric strength and endurance under high voltages. ${ }^{9}$ These improvements can be due to numerous phenomena, mainly stemming from the large interfacial area introduced by nanofillers incorporated into the polymeric matrix ${ }^{10}$ as well as the alteration of the polymer/filler interface properties. ${ }^{9}$ The later can be controlled by changing the type and surface chemistry of the nanoparticles. Due to the polar surface of the above-mentioned nanoparticles, these are prone to adsorb moisture and other polar species (e.g., byproducts of production and surface treatment), which can be detrimental to the dielectric properties. ${ }^{11,12}$ In this regard, nanoparticles such as fumed silica are more favorable due to their low moisture and high purity. Moreover, it has been shown that silica-filled nanocomposites exhibit high electron-phonon interaction at their interface with the surrounding polymer chains, ${ }^{13}$ which is another reason to favor fumed silica over other available nanoparticles. To improve their dispersion and tailor the interfacial properties close to the nanoparticles, the filler surface can be modified with certain functional groups. This can influence nucleation and crystallinity, ${ }^{14}$ mobility of species, ${ }^{15}$ and entanglement density in the interfacial region. ${ }^{16,17}$ Consequently, changes in the nanoparticles' surface properties can lead to improvements in the dielectric properties of the nanocomposites. ${ }^{18}$

Functionalization of nanoparticles can improve the dielectric properties of the nanocomposites by enhancing the filler dispersion in the polymeric matrix: in case of a DC field, due to the differences in electrical conductivity of the composite's components, the electric field tends to bend toward the particles, leading to local electric field concentration.

Received: April 2, 2020

Accepted: July 22, 2020

Published: July 22, 2020 
Furthermore, due to the polarization of interfaces, an additional long-range attractive force is imposed on the charge carriers and draws them to the nanoparticles. ${ }^{19}$ So, in fact, nanoparticles act as electrical defect centers in polymer nanodielectrics. ${ }^{20}$ The extent of this local field concentration, however, is not only a factor of the difference in permittivity (in case of AC fields) or conductivity (in case of DC) between the particles and the polymer matrix, but also of the particle size, their aggregation, and agglomeration. ${ }^{1}$ Improving the dispersion of the nanofillers can lead to the improvement of the dielectric breakdown strength. However, filler dispersion is difficult to control and tends to vary significantly as it is affected by several factors, e.g., the surface energy of the filler, polymer melt viscosity, and processing conditions. ${ }^{21,22}$

Another phenomenon through which surface modification of the nanoparticles can affect the dielectric properties of the nanocomposites is the alteration of the electron-phonon interactions at the filler-polymer interface. This can be achieved, e.g., by the introduction of polar functional groups at the interface. ${ }^{23,24}$ Siddabattuni et al. $^{25}$ investigated epoxy nanocomposites with $\mathrm{TiO}_{2}$ and $\mathrm{BaTiO}_{3}$ nanoparticles, and observed that upon introduction of electron-withdrawing phenyl groups at the polymer-particle interface, the leakage current and dielectric loss was significantly reduced. This also led to an improvement in the dielectric breakdown strength. Huang et al. ${ }^{2}$ noticed that the amount of space charges in linear low-density polyethylene (LLDPE)/silica nanodielectrics was decreased by the attachment of dimethyldichlorosilane to the surface of the silica nanoparticles. Ma et al. ${ }^{1}$ reported a much higher dielectric breakdown strength and improved space charge distribution by the introduction of amine functional groups to the surface of $\mathrm{TiO}_{2}$ nanoparticles incorporated in a low-density polyethylene (LDPE) matrix. Furthermore, the density of the trap states, and as a result, the space charge distribution can be altered upon grafting species with polar functional groups onto the nanoparticle surface, influencing the mobility of charges by the introduction of shallow trap sites ${ }^{26}$ or reducing the number of deeply trapped charges ${ }^{1}$ in the filler-polymer interaction zones. Yamano et al. $^{27}$ found that the addition of $5 \times 10^{-6} \mathrm{~mol} \mathrm{~g}^{-1}$ of an azocompound increased the breakdown strength of LDPE by about $200 \mathrm{MV} \mathrm{m}^{-1}$ at temperatures lower than $30{ }^{\circ} \mathrm{C}$. They attributed this increase to either the trapping effect or the excitation effect of the azocompounds, which acted as electric dipoles. The incorporation of polar groups into insulation systems and its positive effect on their dielectric properties have also been studied in our recent work. ${ }^{17}$ Accordingly, it can be hypothesized that attaching a polar functionality to the surface of the nanoparticles can induce this sort of electronic behavior as the dipoles at the particle-polymer interface may affect charge carrier transport and trapping. ${ }^{4}$ Recent studies have shown that the localized state (trap state) in polymer dielectrics has substantial effects on the charge transport under a high field, and can be closely addressed to the macroscopic dielectric properties including charge injection, space charge distribution, and mobility of charge carriers. ${ }^{28,29}$ Therefore, it is expected that adding certain polar chemical functionalities to the polymer-filler interface will introduce new electronic states and alter the spatial and energy distribution of the localized states in the system, which may account for the changes in dielectric properties of nanofilled dielectrics.

Space charge behavior in an insulating polymer is also closely related to carrier traps located at the interfaces that are induced as a result of crystallization in semicrystalline polymers. $^{30}$ The morphology of these interfaces would significantly affect trap density, trap depth distribution, and charge carrier mobility. ${ }^{31}$ Therefore, by engineering the crystallinity of a nanodielectric, it is possible to control the aforementioned properties. A promising way to control crystallinity in a polymer nanocomposite is through engineering the surface properties of the nanoparticles. Grafting polymers or silane-modifying agents onto the silica surface has been proven to effectively improve its nucleating ability, which results in higher spherulite density within the nanocomposite. $^{32,33}$ This could have beneficial influences on the amount and distribution of the space charges.

The morphological changes in nanocomposites can also be a result of polymer blending, which has recently become especially relevant for new polypropylene (PP)-based highvoltage direct-current (HVDC) cable insulation materials for improving certain mechanical properties. While PP has shown promising dielectric performance, its inherent rigidity, especially at low temperatures, hinders its utilization for this application. $^{34,35}$ This necessitates blending PP with another polymer with more suitable mechanical properties such as polyolefin elastomers. In regards to nanocomposite systems with a polymer blend as the matrix, studying the crystallinity and morphology effects is of great importance, especially when the nanoparticles have been subjected to surface modification.

In this study, silica nanoparticles are modified with 3aminopropyltriethoxysilane (APTES), a polar modifying agent, and compounded with $\mathrm{PP} /$ (ethylene-octene) copolymer (EOC) polymer blends. The aim of surface modification is twofold: on the one hand, it is speculated that the amine functional group in APTES is prone to alter the interactions and electronic features at the silica-polymer interface. As a consequence, the trapping properties of the interface undergo meaningful changes, which might induce beneficial influences on the bulk insulation characteristics of the nanocomposite materials. On the other hand, by engineering the nanofiller surfaces, their nucleating ability and hence the crystallinity of the nanodielectric can be controlled. This way, an optimized modification reaction to control the trap states and the space charge phenomena could be developed. First, the silica modification is evaluated using thermogravimetry analysis (TGA), Fourier-transform infrared (FTIR) spectroscopy, Xray photoelectron spectroscopy (XPS), and transmission electron microscopy (TEM). Subsequently, the influence of silica modification on the dielectric response of the material is investigated with broadband dielectric spectroscopy (BDS). Charge trapping properties of the aforementioned nanocomposites are also studied via thermally stimulated depolarization current (TSDC) measurements. Since the charge trapping behavior can be significantly influenced by the crystalline structure, differential scanning calorimetry (DSC) was performed to study the crystalline structure in detail.

\section{EXPERIMENTAL SECTION}

2.1. Silica Modification. A high purity, low moisture content fumed silica grade, AEROSIL 200 (Evonik Industries, Germany), was used as the filler for this study. The silica functionalization was carried out in a liquid phase (toluene) using 3-aminopropyltriethoxysilane (APTES) as a modifying agent (Sigma-Aldrich, 99\%). The reaction took place in a glass round bottom flask immersed in an oil heating bath and equipped with a mechanical stirrer, a cooler, and a 
(a)

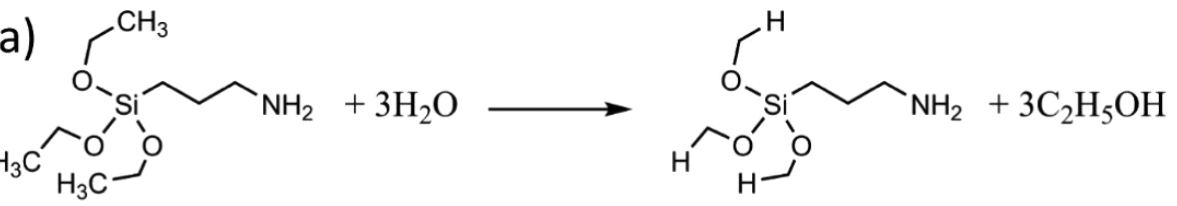

(b)

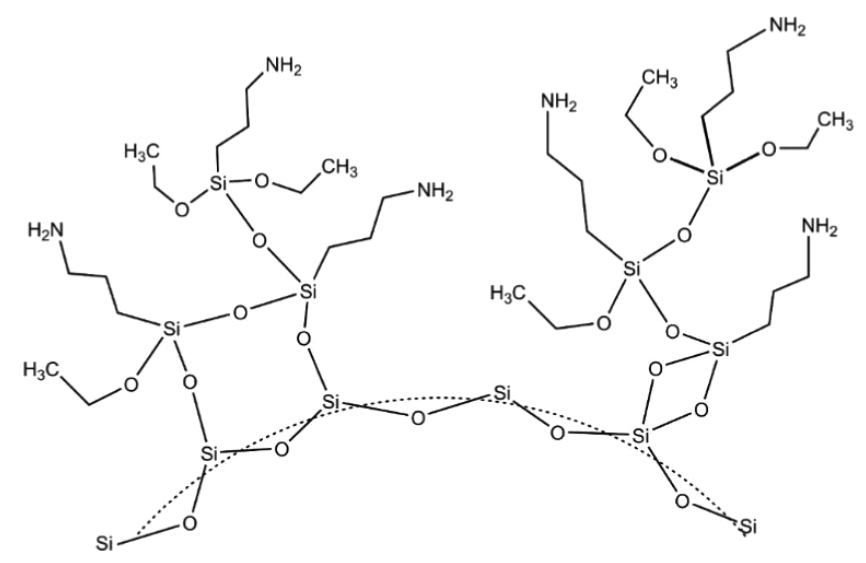

(c)
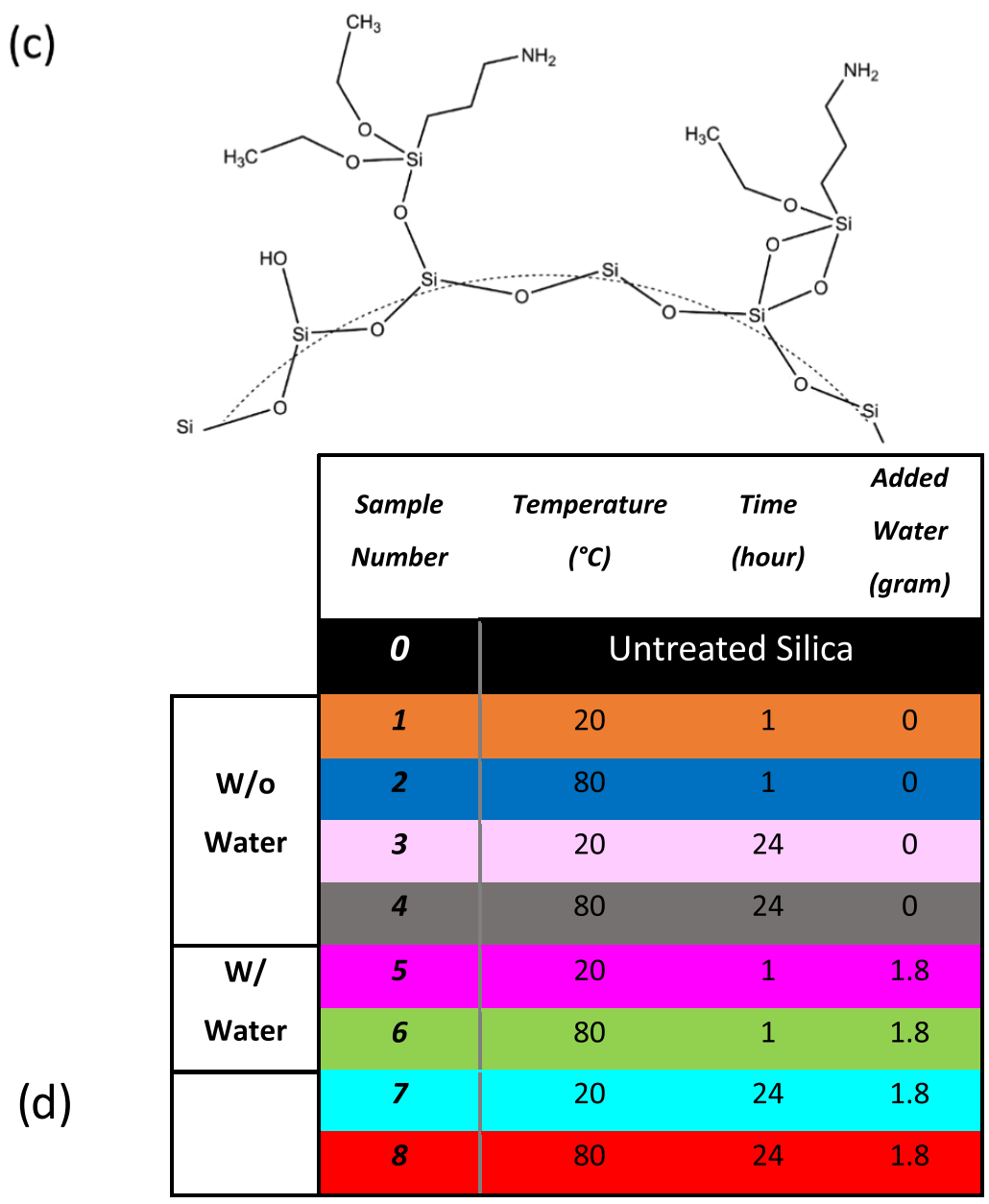

Figure 1. (a) Hydrolysis and reaction of APTES with silica (b) with and (c) without condensation and (d) reaction conditions utilized for modification of the silica nanoparticles.

thermometer. The reaction conditions were varied to control the amount and morphology of the grafted silane on the silica. Temperature, time, and the amount of added water were chosen as the most effective parameters. Reactions were carried out at 20 and 80 ${ }^{\circ} \mathrm{C}$, for 1 or $24 \mathrm{~h}$, with and without a stoichiometric amount of water for hydrolysis of the silane. The APTES content in the solution was 
calculated as twice the amount needed for covering the silica with a monolayer. The details of the modification reactions are depicted in Figure 1. In general, anhydrous systems with only a trace of water and low silane concentrations were desirable for the preparation of smooth APTES-derived silane layers. ${ }^{36}$ Silica, silane, and additional water were mixed with toluene as the medium of the reaction. The purity of the toluene was $98 \%$, and it was used without further purification.

With water present in the reaction, hydrolysis and subsequently condensation of APTES is very likely. Therefore, different APTES film morphologies can be expected, depending on whether or not water is involved in the reaction. Figure 1 shows the APTES hydrolysis and its grafting onto the silica surface with and without condensation.

2.2. Preparation of the Nanocomposites. The nanocomposites studied in this work were based on polypropylene/ethylene-octene copolymer (PP/EOC) blends filled with functionalized silica nanoparticles. The nanocomposite preparation was done by adding $1 \mathrm{wt} \%$ of the silica as well as an antioxidant package to the polymer matrix in a twin-screw micro extruder, and injecting it into a square mold using a mini-injection molding machine. The mold dimensions were $26 \times 26 \times 0.5 \mathrm{~mm}^{3}$. The nanocomposite $(\mathrm{NC})$ samples were numbered according to the silica sample incorporated. For instance, NC_1 nanocomposite was filled with silica sample number 1 .

2.3. Silica Characterization. Thermogravimetric analysis (TGA) was utilized to quantify the level of modification. The silica samples were heated from room temperature to $850{ }^{\circ} \mathrm{C}$ in an air atmosphere with a rate of $20^{\circ} \mathrm{C} \mathrm{min}{ }^{-1}$ while the mass loss of the sample was being measured. The mass loss between 300 and $850{ }^{\circ} \mathrm{C}$ can be attributed to thermal decomposition of APTES chemically attached to the silica surface. ${ }^{37}$ Fourier-transform infrared (FTIR) spectroscopy was utilized in diffuse reflectance mode using a Perkin Elmer Spectrum 100 with a diffuse reflectance accessory. The samples were prepared using potassium bromide (KBr; 99+\%, FTIR grade, Harrick Scientific Corporation) as a background. Spectra were recorded from 4000 to $400 \mathrm{~cm}^{-1}$ and averaged over 128 scans, using a resolution of $4.0 \mathrm{~cm}^{-1}$. All of the tests were performed at room temperature. X-ray photoelectron spectroscopy (XPS) was conducted by means of a PHI Quantera scanning X-ray microscopy. This method is based on irradiating a material with a beam of X-ray, while simultaneously measuring the kinetic energy and number of electrons that escape from the surface (up to $10 \mathrm{~nm}$ in depth) of the material being analyzed. This way, it is possible to determine the atomic composition of the deposited film on the silica. Transmission electron microscopy (TEM), including energy-filtering mode (EFTEM), was performed on the modified silica nanoparticles, using a Philips CM300ST-FEG transmission electron microscope to take a closer look at the modified silica surface.

2.4. Broadband Dielectric Spectroscopy (BDS). The real and imaginary parts of permittivity $\left(\varepsilon_{\mathrm{r}}^{*}=\varepsilon_{\mathrm{r}}^{\prime}+\mathrm{i} \varepsilon_{\mathrm{r}}^{\prime \prime}\right)$ were measured using a Novocontrol Alpha-A dielectric analyzer within the frequency range of $10^{-2}-10^{6} \mathrm{~Hz}$ and under an applied voltage of $1 \mathrm{~V}$. All of the measurements were conducted at room temperature. Circular gold ( $\mathrm{Au})$ electrodes (100 $\mathrm{nm}$ in thickness) were deposited on both sides of the sample films by e-beam evaporation under high vacuum, and they were short-circuited and kept in a vacuumized desiccator overnight prior to the measurements.

2.5. Thermally Stimulated Depolarization Current (TSDC). The thermally stimulated depolarization current (TSDC) method was used to study the charge trapping and transport in the nanocomposites. The nanocomposite specimens were first heated up to 70 ${ }^{\circ} \mathrm{C}$, and then a $3 \mathrm{kV} \mathrm{mm}{ }^{-1} \mathrm{DC}$ electric field was applied for $20 \mathrm{~min}$ under isothermal conditions. The samples were then cooled down to $-50{ }^{\circ} \mathrm{C}$ while the electric field was still on. Subsequently, the samples were short-circuited and linearly heated up to $140{ }^{\circ} \mathrm{C}$ at $3{ }^{\circ} \mathrm{C} \mathrm{min}{ }^{-1}$ while the depolarization current was being measured by an ammeter.

2.6. Morphology and Crystallinity Analysis. Scanning electron microscopy (SEM) was performed on the nanodielectric composites by means of a Zeiss MERLIN HR-SEM to study the filler dispersion and the polymer blend morphology. The silica size distribution was analyzed using open-source ImageJ software with Trainable Weka Segmentation plugin. ${ }^{38}$ Differential scanning calorimetry (DSC) was performed using a Netzsch DSC 214 Polyma. Samples were subjected to two heating/cooling cycles, from -50 to $200{ }^{\circ} \mathrm{C}$. The heating/ cooling rate was set at $3{ }^{\circ} \mathrm{C} \mathrm{min}^{-1}$, similar to the heating rate in TSDC. This approach enabled us to compare the thermal transitions and crystalline melting of the samples under similar dynamic heating conditions as during the thermally stimulated depolarization measurements.

\section{RESULTS AND DISCUSSION}

3.1. Characterization of Nanoparticles. The TGA graphs depicted in Figure 2a,c show a higher mass loss for
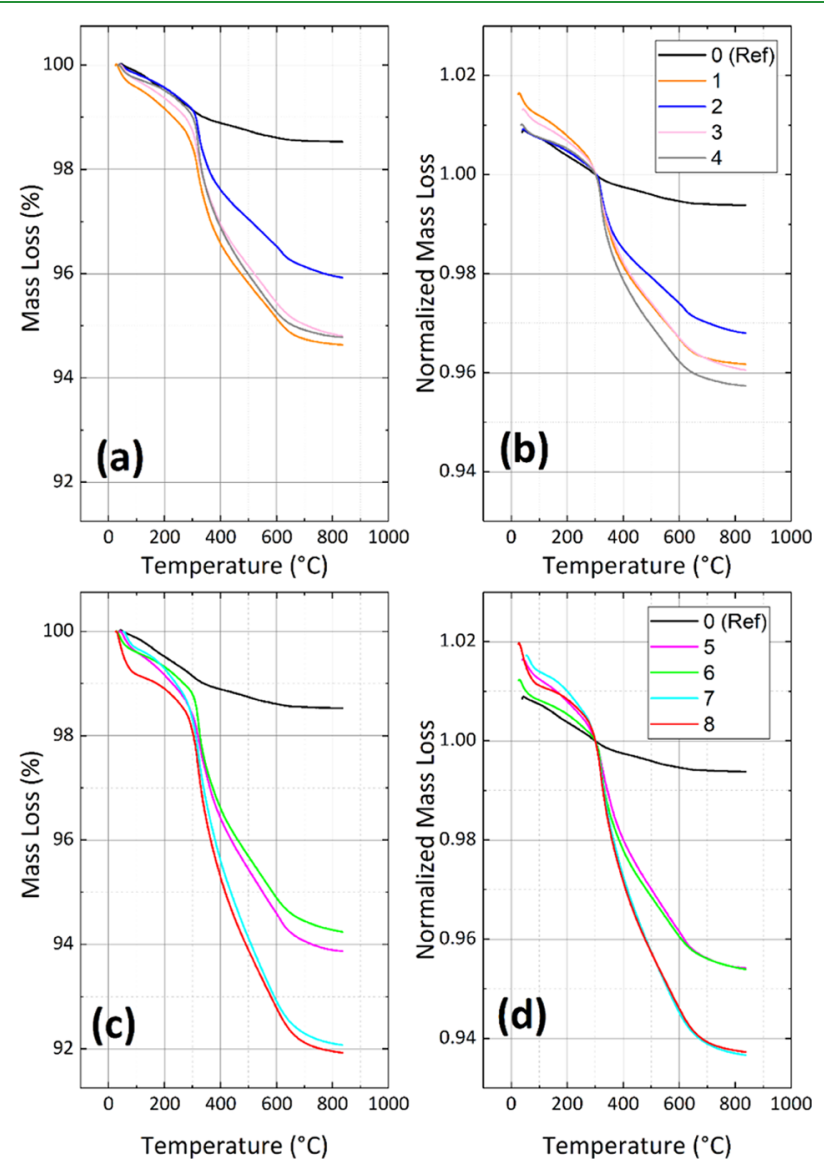

Figure 2. (a, c) TGA graphs for the modified silica samples compared to the untreated silica and (b, d) TGA mass loss normalized to the mass loss at $300{ }^{\circ} \mathrm{C}$.

the modified silica samples compared to the unmodified sample, indicating the successful treatment of the silica surface. To compare the amount of grafted silane for different samples, the TGA mass loss data was normalized against the value at $300{ }^{\circ} \mathrm{C}$ (Figure $\left.2 \mathrm{~b}, \mathrm{~d}\right)$.

The mass loss below $300{ }^{\circ} \mathrm{C}$ is related to the removal of nonchemically bonded compounds and volatiles. On the one hand, it can be seen that the mass loss ranges between 3.2 and $4.2 \%$ when the reaction takes place with no additional water in the system. This indicates that the silanization reaction can take place even in the absence of excess water ${ }^{39}$ because of the self-catalyzing nature of APTES due to hydrogen bond interactions of the amine moiety with the silanol groups on the silica surface. ${ }^{40}$ It also seems, in this case, that the grafting of the APTES is not significantly affected by the change in the 

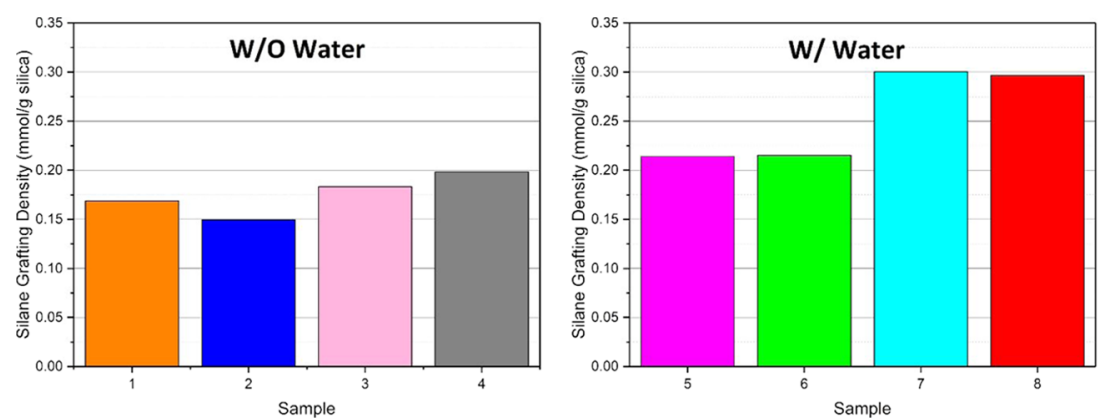

Figure 3. Values of silane grafting density for different modified silica samples.
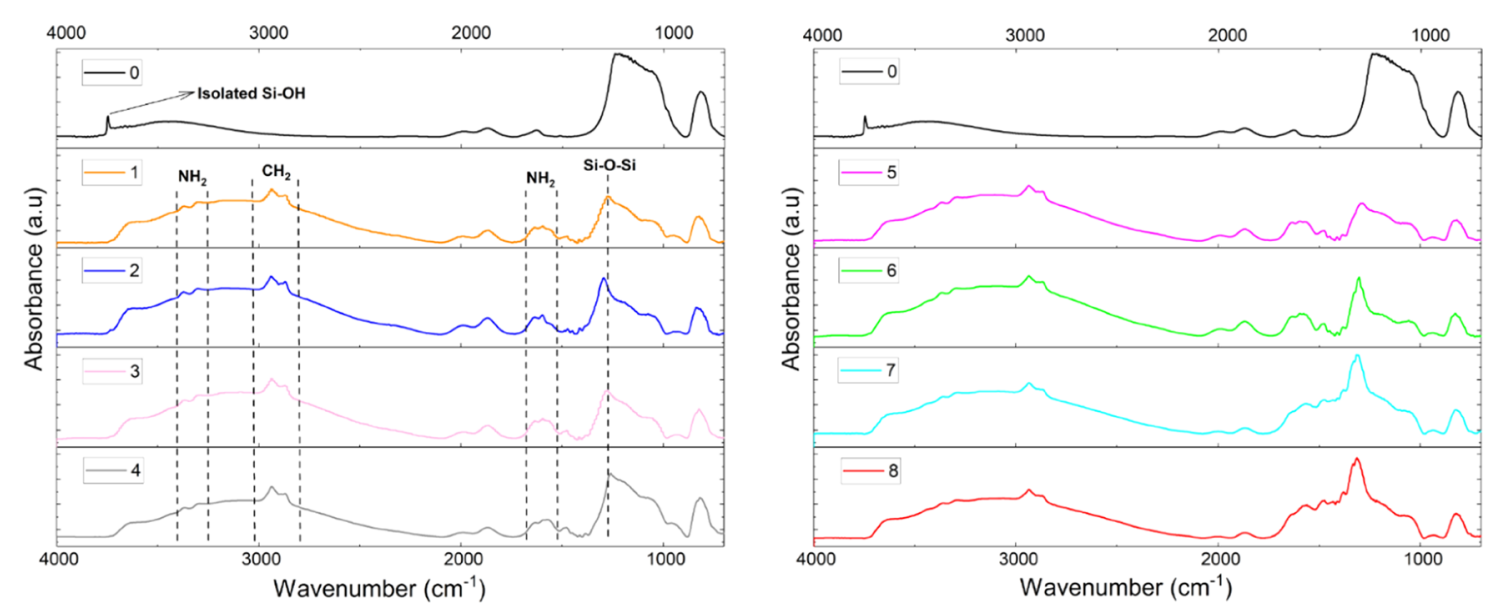

Figure 4. FTIR spectra of the untreated and treated silica samples.

a.

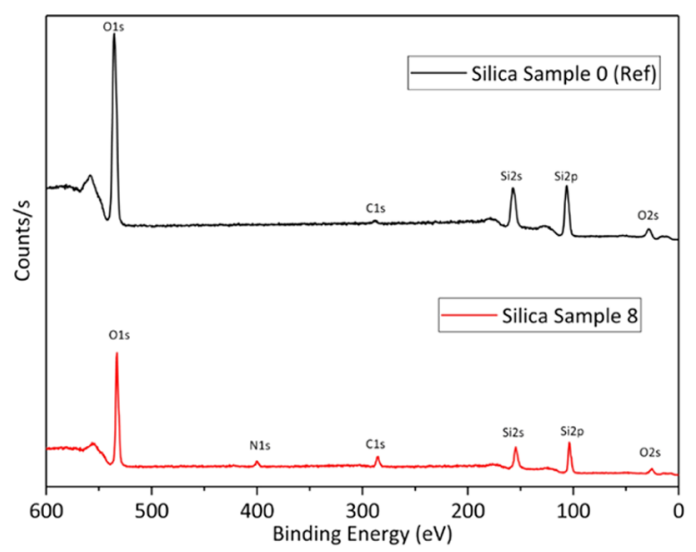

b.
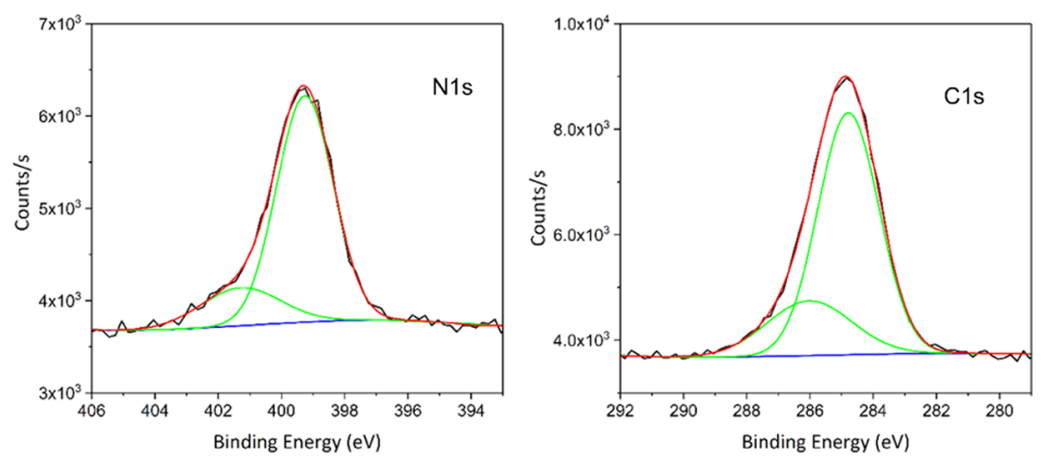

Figure 5. (a) XPS full spectra of the modified and unmodified silica samples and (b) X-ray photoelectron spectra for fine scans of silica sample 8. 
reaction time or temperature. In the presence of excess water, on the other hand, a higher value of weight loss, $6.4 \%$, is achieved for the samples modified for $24 \mathrm{~h}$. However, with the reaction time kept constant, no difference is observed in the values of mass loss upon increasing the temperature. The values of silane grafting density in $\mathrm{mmol} \mathrm{g}^{-1}$ silica, as shown in Figure 3, can better demonstrate this observation. These values are calculated based on the TGA, using eq 1

$$
\text { APTES grafting density }\left(\frac{\mathrm{mmol}}{\mathrm{g} \text { silica }}\right)=\frac{\Delta W \times 1000}{M_{\mathrm{w}} \times(100-\Delta W)}
$$

where $\Delta W$ is the mass loss between 300 and $850{ }^{\circ} \mathrm{C}$ and $M_{\mathrm{w}}$ is the molecular weight of APTES, $221.37 \mathrm{~g} \mathrm{~mol}^{-1}$.

FTIR spectra of the modified silica nanoparticles also confirm the chemical attachment of the APTES to the silica surface. The spectra for all of the studied samples are shown in Figure 4. The bands at 3300,2850 , and $1600 \mathrm{~cm}^{-1}$ correspond to $\mathrm{N}-\mathrm{H}$ stretching, $\mathrm{C}-\mathrm{H}$ stretching, and $\mathrm{N}-\mathrm{H}$ bending, respectively. This proves the presence of chemically bonded APTES on the silica surface. The sharp band at $3700 \mathrm{~cm}^{-1}$ (isolated $-\mathrm{OH}$ ) and the broadband at $3500 \mathrm{~cm}^{-1}$ representing the free and intermolecular hydroxyl groups almost completely vanished upon modification. This significant difference indicates that the surface of the modified silica is less hydrophilic and well covered by the chemically attached silane-modifying agent.

The XPS spectra of silica sample 8 are shown in Figure 5a along with the spectra from the untreated silica for comparison. The emergence of the peaks corresponding to $\mathrm{C} 1 \mathrm{~s}$ and $\mathrm{N} 1 \mathrm{~s}$ in sample 8 confirms the presence of APTES on the silica surface. The small $\mathrm{C} 1 \mathrm{~s}$ peak in the reference sample is present due to contaminations or traces of carbon dioxide in the equipment chamber. Elemental fine scans in Figure $5 b$ indicate the atomic environment and are dependent on the chemical bonds in the film. As expected, the $\mathrm{N} 1 \mathrm{~s}$ fine scan reveals that there are two peaks at 398.2 and $401.3 \mathrm{eV}$, indicative of nitrogen bonded with carbon and hydrogen, respectively. The $\mathrm{C}$ 1s scan also exhibits two peaks at 284.8 and $286.0 \mathrm{eV}$. These peaks represent two types of carbon bonds in the APTES film, namely, $\mathrm{C}-\mathrm{C}$ and $\mathrm{C}-\mathrm{N}$. Therefore, the XPS data also confirm successful deposition of chemically bonded APTES on silica nanoparticles.

Energy-filtered transmission electron microscopy (EFTEM) was performed on the silica samples to analyze the silica surface structure after modification via elemental mapping. Carbon mapping of the modified silica in Figure 6 shows the APTES propyl chain distributed along the surface where the concentrated regions are indicative of APTES island growth on the silica surface.

\subsection{Characterization of PP/EOC/Silica Nanocompo-} sites. Treating the silica with APTES can result in less hydrophilic nanoparticles. So, varying the grafting density of APTES can affect the silica dispersion in the polymer matrix. Therefore, filler dispersion in the nanocomposites with low (NC_1 and NC_2) and high (NC_7 and NC_8) levels of APTES grafting density was compared to $\overline{\mathrm{N}} \mathrm{C} 0$ (with unmodified silica) using SEM. The corresponding images are depicted in Figure 7. It is observed that the polymer matrix exhibits a well-distributed two-phase morphology: a well dispersed sea-island structure with EOC elongated in the direction of the flow. This sort of structure is usually observed

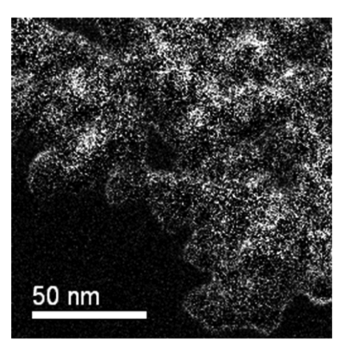

Silica Sample 7

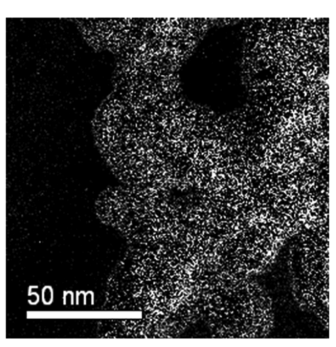

Silica Sample 8
Figure 6. EFTEM carbon mapping for silica samples 7 and 8 .

in immiscible injection-molded polymer blends. When the molten material enters the cavity in a parabolic profile, the material in the front, undergoing considerable stretching, is deposited on the wall as an immobile frozen layer. Subsequently, as the rest of the molten material flows through this envelope, the dispersed phase is elongated in the direction of the flow. ${ }^{41,42}$ Despite the immiscibility, the blends of PP with ethylene-based copolymers have been shown to have superior dielectric breakdown strength compared to the each base material. ${ }^{43}$ Therefore, the phase-separated morphology in our studied nanocomposites is presumed to have no deteriorating effect on the dielectric properties of the system. The dispersion histograms in Figure 7 also shows that the mean silica cluster size reduces from ca. 300 to $120 \mathrm{~nm}$ upon modification of the nanoparticles. This indicates that modifying the silica with APTES results in relatively better dispersion of the nanoparticles. Moreover, to the extent SEM can detect, different grafting densities do not significantly influence the dispersion quality of the silica. This can be a side effect of the polarity of the silane modifying agent. The silica clusters are well distributed throughout the matrix, mostly located in the PP phase. This phenomenon is also detected in the DSC results, which will be discussed in the following sections.

Dielectric properties in nanocomposite insulating materials are highly influenced by the dynamics of interfacial interactions in the system. These interactions can affect measurable macroscopic properties such as permittivity and dielectric loss. Therefore, BDS was applied to study the underlying physics of the dielectric phenomena in our studied nanocomposites. Dielectric spectroscopy results are depicted in Figure $8 \mathrm{a}-\mathrm{c}$, where real $\left(\varepsilon_{\mathrm{r}}^{\prime}\right)$ and imaginary $\left(\varepsilon_{\mathrm{r}}{ }^{\prime \prime}\right)$ parts of the relative permittivity as well as the loss tangent $(\tan \delta)$ are plotted against the frequencies of the applied field. Also, to further realize the relaxation processes in the nanocomposites, a Cole-Cole plot is shown in Figure 8d. In general, the variations in $\varepsilon_{\mathrm{r}}{ }^{\prime}, \varepsilon_{\mathrm{r}}{ }^{\prime \prime}$, and $\tan \delta$ with respect to the frequency are determined by the dipolar molecular relaxations of the polymer chains, filler, or any other species in the system, as well as the interfacial polarizations (related to space charge relaxations), depending on the frequency range. The dipolar relaxations are mainly predominant at higher frequencies, whereas the interfacial polarizations can be characterized in the lowfrequency range (usually below $1 \mathrm{~Hz}$ ). Therefore, a broad range of frequencies, $10^{-2}-10^{6} \mathrm{~Hz}$, was applied for the permittivity measurements.

In Figure 8a, it is observed that the introduction of untreated silica (NC_0) increases the permittivity at frequencies higher than $1 \mathrm{~Hz}$ compared to the unfilled polymer (UP). This can be a result of the adsorbed moisture on the silica, hydrogen bonded to the silanol groups. A low grafting density of APTES 

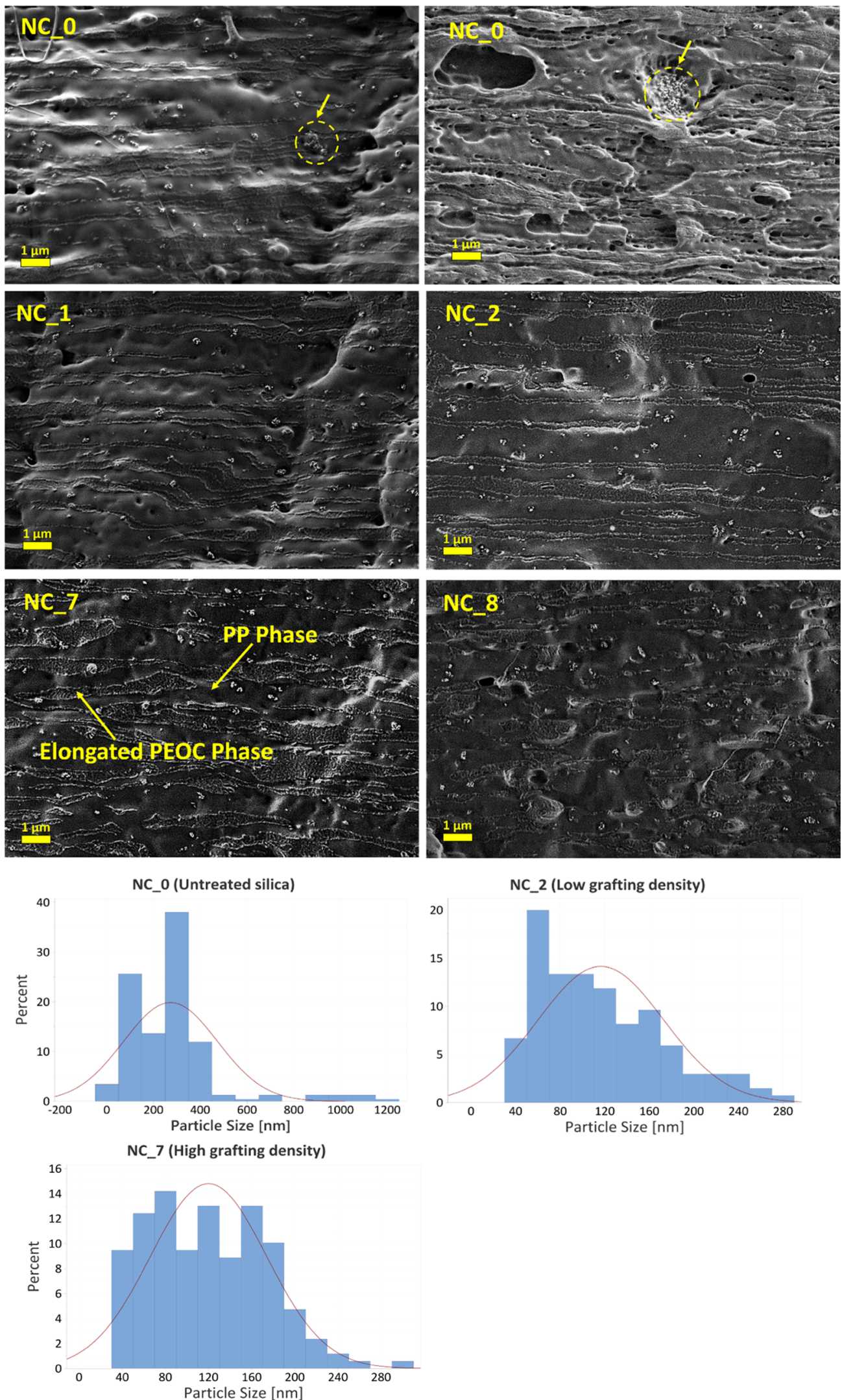

Figure 7. SEM images of nanocomposites with untreated silica (NC_0), low (NC_1 and NC_2), and high (NC_7 and NC_8) APTES grafting densities (top). Silica cluster size distribution histograms (bottom). A wide range of particle sizes are observed for NC 0 (mean: $297.7 \mathrm{~nm}$ ), whereas the modified samples exhibit a narrow distribution (mean: $115 \mathrm{~nm}$ ).

decreases this effect, resulting in a lower permittivity for NC_2 compared to NC_0. However, increasing the APTES grafting density (NC_7) leads to permittivity values even higher than the nanocomposite with unmodified silica. This is due to the 

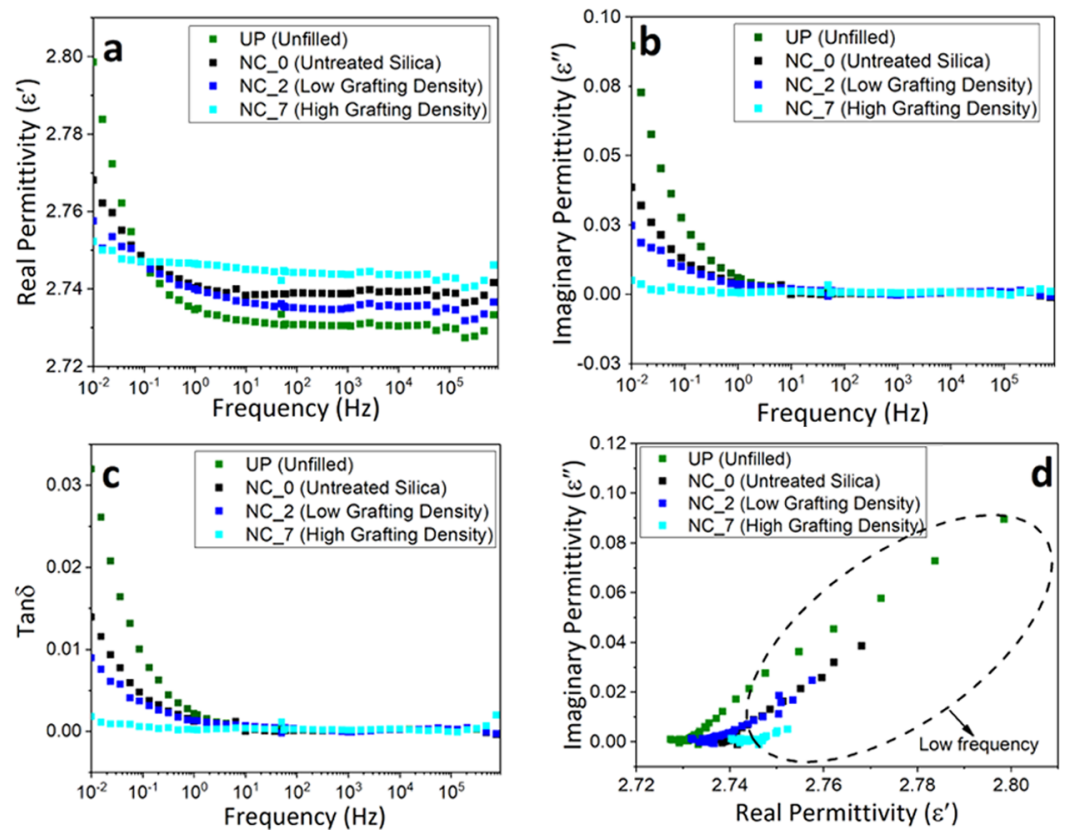

Figure 8. $(\mathrm{a}-\mathrm{c})$ Real and imaginary parts of permittivity as well as the loss tangent $(\tan \delta)$ plotted with respect to the frequencies and (d) representative Cole-Cole plots for the studied dielectric systems.

presence of the grafted APTES oligomers on the silica, contributing to the dipolar relaxations of the material. A frequency-dependent behavior is observed in the real permittivity characteristics, manifested as a steep increase at low frequencies. This increase can be either due to polarization of relatively bigger dipolar species (e.g., contaminations, byproducts of filler modification, etc.), or occurrence of Maxwell-Wagner or space charge polarizations. ${ }^{44}$ Another indicator of space charge polarizations, in addition to the steep increase in $\varepsilon_{\mathrm{r}}{ }^{\prime}$, is the emergence of relaxation peaks in $\varepsilon_{\mathrm{r}}{ }^{\prime \prime}$ and $\tan \delta$ characteristics of the material. ${ }^{13}$ Since these measurements are done at room temperature, no distinct relaxation peak is observed in $\varepsilon_{\mathrm{r}}{ }^{\prime \prime}$ or $\tan \delta$ (Figure $8 \mathrm{~b}, \mathrm{c}$ ), as they would be likely to appear at frequencies lower than the measurement range. Nevertheless, an enhancement is observed in the imaginary permittivity and the loss factor at low frequencies. These combined trends of $\varepsilon_{\mathrm{r}}{ }^{\prime}, \varepsilon_{\mathrm{r}}{ }^{\prime \prime}$, and $\tan \delta$ suggest that there can be an effect of DC conductivity and the occurrence of space charge polarization in the studied systems. Interestingly, the slope of these enhancements at low frequencies tends to be lower for the nanocomposites compared to the base polymer. The enhancement slope in $\varepsilon_{\mathrm{r}}{ }^{\prime}, \varepsilon_{\mathrm{r}}{ }^{\prime \prime}$, and $\tan \delta$ for the nanocomposites tends to decrease further by increasing the APTES grafting density to the point where only a marginal increase is observed in case of $\mathrm{NC}_{7} 7$ with high grafting density. This suggests that the addition of nanoparticles and the introduction of the amine functionality result in either a reduction in the mobility of free polar species in the matrix and/or a suppression in the interfacial polarizations in the nanocomposites. The same trend can also be observed in the Cole-Cole plot, as shown in Figure $8 \mathrm{~d}$. The lowering of the slope in the low-frequency region, in case of the nanocomposites, can be an indication of a lower contribution of DC conductivity in these systems, ${ }^{45}$ which is more pronounced in case of nanocomposites with APTES-modified silica.

Figure 9a,b shows the TSDC plots for the silica-filled NCs as well as of the unfilled polymer (UP) as a reference along with trap level/density distribution calculated using a numerical method presented by Tian et al. ${ }^{46}$

Principally, the TSDC spectra represent the relaxation of the polarized species as well as the accumulated space charge as a result of the electric field. The peaks emerging at temperatures above the glass transition of the semicrystalline polymers are mainly attributed to the relaxation of the space charge trapped at the interfaces. Upon softening/melting transitions, the trapped charges can be stimulated, and as a result, a peak appears in the current measured by the ammeter. To a first approximation, the temperature and intensity of a TSDC peak can be associated with the depth and density of charge traps, respectively.

The spectra depicted in Figure 9a,b indicate that by incorporating the treated silica, the TSDC behavior becomes more complex. It is observed that the main TSDC peak shifts toward higher temperatures, indicating that the trap level becomes deeper. In general, in case of samples with the amine functionality on the silica surface, another TSDC peak emerges at around $93-97{ }^{\circ} \mathrm{C}$, being indicative of induction of a new deep trap, while a small shoulder is observed around the same temperature $\left(\sim 78{ }^{\circ} \mathrm{C}\right)$ as the main TSDC peaks of the reference samples (UP and NC_0). Comparing NC_2 and $\mathrm{NC} 7$ with the lowest and the highest APTES grafting density on silica, respectively, it can be observed that in case of NC 7, the peak temperature of the TSDC peak is shifted to higher temperatures (deeper trap level). This can result in lower charge mobility in the composites. Moreover, the intensity of the TSDC peak is seen to vary significantly depending on the APTES grafting density, with some of the samples exhibiting a reduction in the main TSDC peak intensity; this may be due to (i) the density of the trap states being reduced or (ii) the space charge distribution becoming more uniform in the nanocomposites. Figure $9 \mathrm{c}$ shows the charging current behavior during the isothermal poling phase for high and low grafting density samples, compared to the references. While it is clear that the polarization step is too short to reach steady-state DC conduction in the reference samples, the transient current 

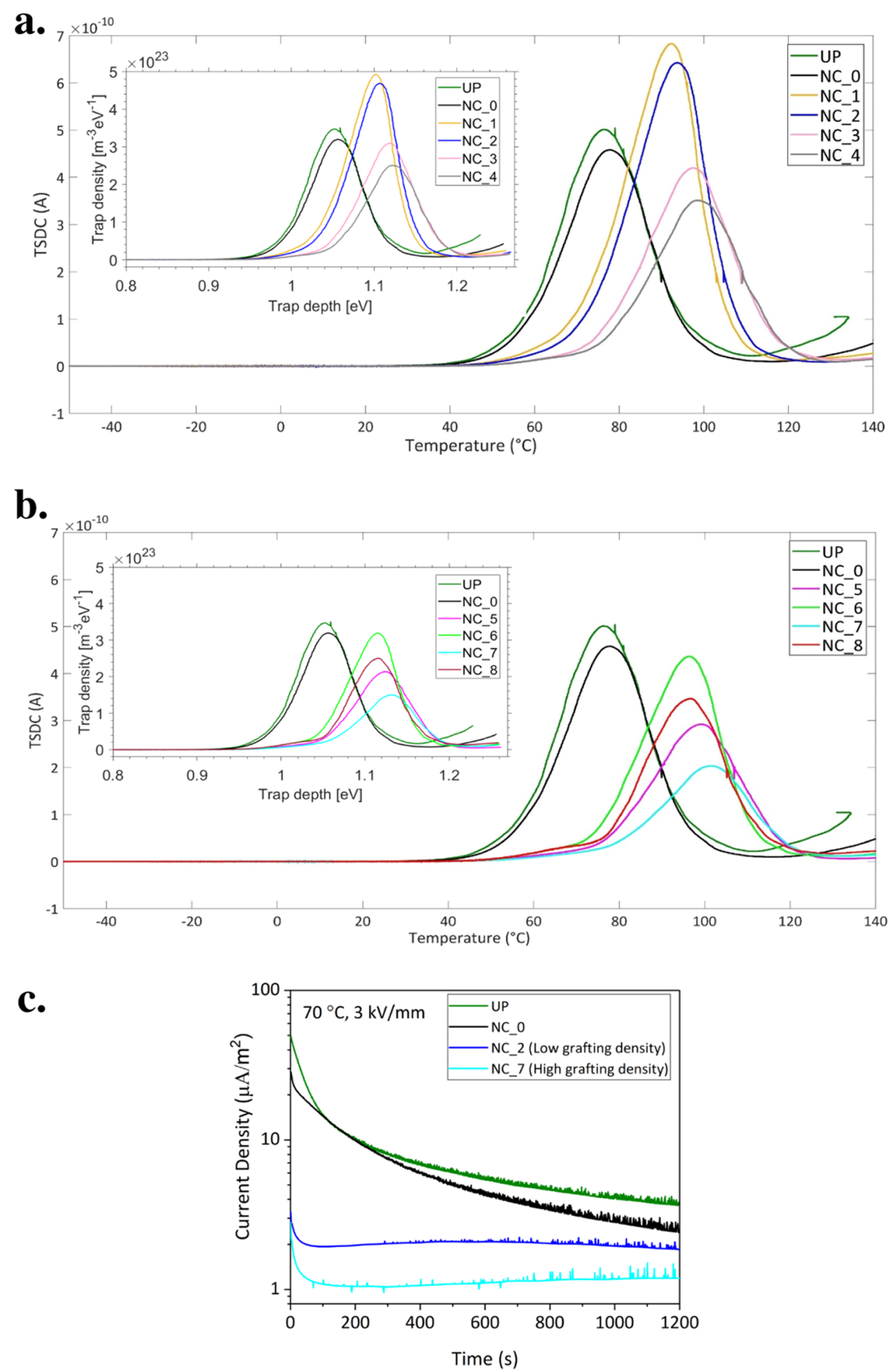

Figure 9. (a, b) TSDC spectra and MTSDC trap level distribution of injection-molded PP/EOC/silica nanocomposites as well as the unfilled reference (UP) and (c) isothermal charging current density during the polarization phase.

densities demonstrate significant differences between the samples. The nanocomposites containing modified nanoparticles show significantly lower current densities, and hence lower apparent conductivity at the end of the poling phase $\left(1.26 \times 10^{-12}, 8 \times 10^{-13}, 6.2 \times 10^{-13}, 3.9 \times 10^{-13} \mathrm{~S} \mathrm{~m}^{-1}\right.$ for UP, NC_0, NC_2, and NC_7, respectively). Accordingly, as it is also suggested by the BDS results, a lower effect of DC conductivity can be another reason for the reduction of the main TSDC peak intensity of the modified samples.

It seems that the apparent depth and density of the traps are not solely influenced by the amount of APTES on the silica surface. This is first observed in the samples NC_1 to NC_4, which contain silica particles with more or less similar APTES grafting densities. The suppressed TSDC peak for NC_3 and NC_ 4 can be due to the longer silica modification time, during 
a.
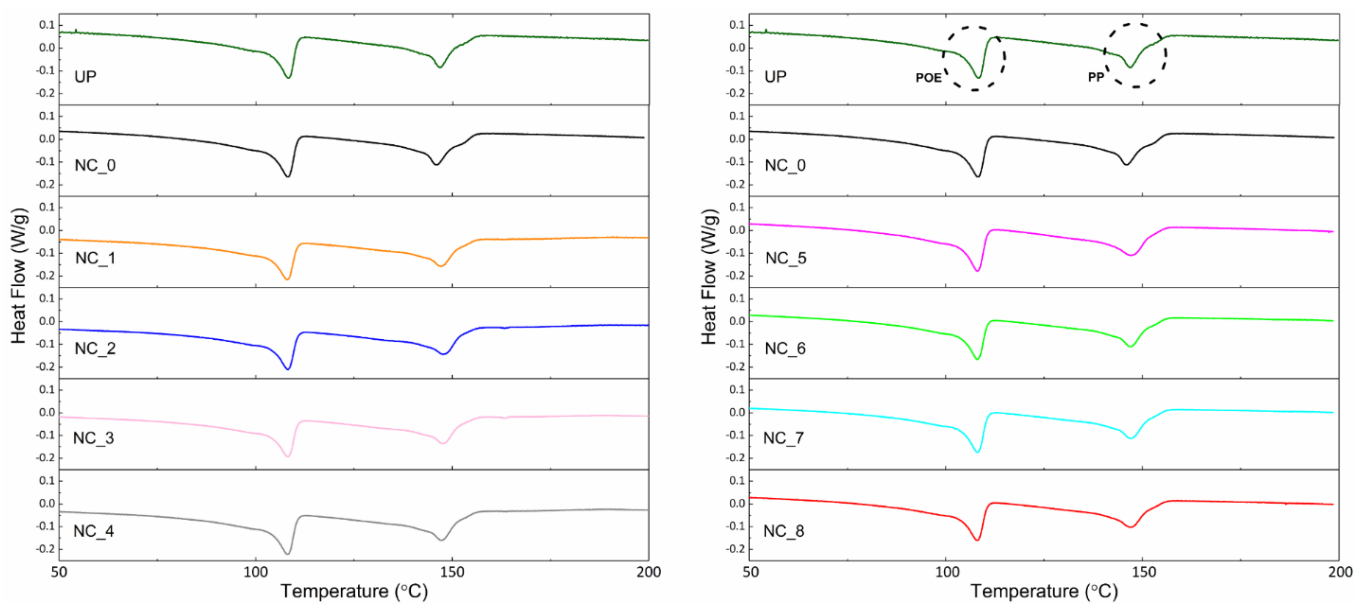

b.
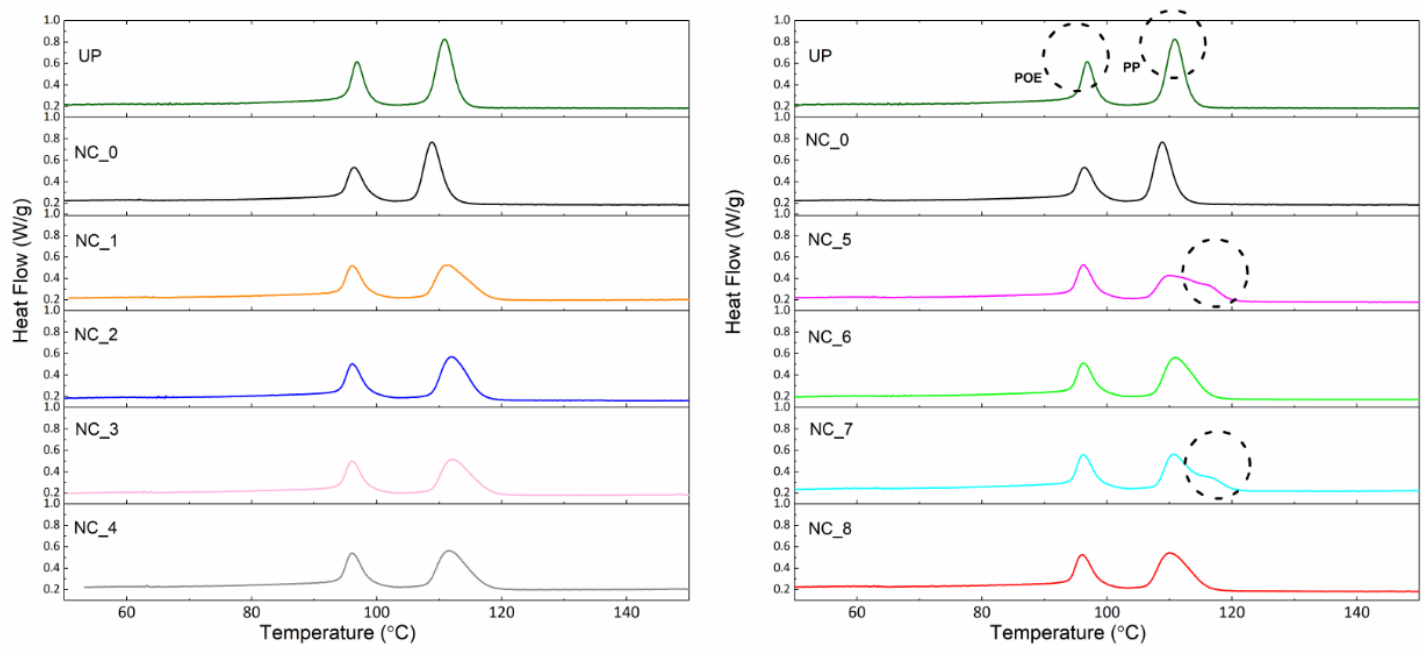

c.

\begin{tabular}{ccccccc} 
Sample & $\begin{array}{c}\mathrm{Tm} \text { Onset } \\
\left({ }^{\circ} \mathbf{C}\right)\end{array}$ & $\begin{array}{c}\text { Tc Onset } \\
\left({ }^{\circ} \mathbf{C}\right)\end{array}$ & $\begin{array}{c}\text { PP Tc } \\
\left({ }^{\circ} \mathbf{C}\right)\end{array}$ & $\begin{array}{c}\text { EOC Tc } \\
\left({ }^{\circ} \mathbf{C}\right)\end{array}$ & $\begin{array}{c}\text { Enthalpy } \\
\text { of Melting } \\
(\mathbf{J} / \mathbf{g})\end{array}$ & $\begin{array}{c}\% \\
\text { Crystallinity }\end{array}$ \\
\hline UP & 102.5 & 115 & 110.9 & 96.9 & 87.4 & 35 \\
\hline NC_0 & 102.1 & 112.2 & 108.7 & 96.7 & 97.8 & 39 \\
\hline NC_5 & 100.5 & 119.7 & 110.1 & 96.5 & 89.9 & 36 \\
\hline NC_6 & 101.4 & 117.5 & 111 & 96.3 & 79.3 & 31 \\
\hline NC_7 & 101.3 & 120.3 & 110.8 & 96.1 & 91.4 & 36 \\
NC_8 & 101.7 & 116.5 & 110.1 & 95.9 & 87.3 & 35 \\
\hline
\end{tabular}

Figure 10. DSC measurements: (a) melting, (b) crystallization curves of the nanocomposites, and (c) DSC parameters of selected nanocomposites.

which condensation of the APTES species is more susceptible. NC 7 and NC 8 also behave differently in terms of TSDC, even though they contain silica samples with similar APTES grafting densities. In case of NC_7, the deep trap TSDC peak intensity is lower compared to $\mathrm{NC} 8$. The same can be observed for samples $\mathrm{NC} 5$ and $\mathrm{NC}^{-} 6$. What differs in the above-mentioned samples is the time and the temperature of the modification reaction, which affects the morphology and conformity of the deposited APTES layer. A possible explanation for this is that the depth and density of the traps are not only a function of the thickness of the silane layer, but also of its morphology. On the one hand, differences in the deposited APTES layer morphology can solely affect the trap depth and density. On the other hand, changes in the filler surface morphology can affect the physical properties of the compounds, e.g., crystallization, which can further affect charge trapping behavior of the system. Therefore, DSC measurements are performed to analyze and compare melting and crystallization processes in depth.

Melting and crystallization curves for the nanocomposites as well as the unfilled blend are depicted in Figure 10. While no noticeable difference is observed in the melting curves (Figure 10a), the crystallization curves (Figure 10b) show some significant changes upon the incorporation of the nanoparticles and changing the modification conditions. Surprisingly, it can be seen that despite the expected nucleating effect of the 
nanoparticles, ${ }^{47}$ the onset of crystallization shifts to a lower temperature after addition of the untreated silica ( $\mathrm{NC} 0$ ). This could be due to the adsorption of the polar antioxidants on the silica surface, resulting in fewer nucleating sites in the polymer matrix. This also results in less restriction for the crystallites to grow, leading to a higher crystal content compared to UP (see Figure 10c). After the silica surface is treated, the onset of crystallization increases by $4-7{ }^{\circ} \mathrm{C}$, indicating that the deposited APTES layer facilitates nucleation. This increase in the onset of crystallization, however, is not to the same extent for all of the samples. Figure 10c shows the DSC parameters for the nanocomposites NC_5 to NC_8, samples with different APTES layer morphologies. It can be seen that $\mathrm{NC} \_5$ and $\mathrm{NC} 77$ exhibit higher crystallization onsets compared to NC_6 and NC_8. This can be explained as follows.

Silica samples 5 and 7 are modified at room temperature, whereas samples 6 and 8 are treated at $80{ }^{\circ} \mathrm{C}$. At lower reaction temperatures, the excess water in the reaction tends to be adsorbed onto the silica surface due to its hydrophilicity. Therefore, the condensation of the APTES and the silanization reaction takes place at the silica surface. This would result in formation of "island-like" structures of APTES on the silica. While the presence of these APTES islands can further contribute to the induction of deep traps, ${ }^{48}$ they can act as individual nuclei, inducing interfacial crystallization. ${ }^{49,50}$ The broadening that is observed in the $\mathrm{NC} \_5$ and $\mathrm{NC}_{-} 7$ crystallization curves can also be explained as nucleation and transcrystallization at the silica/polymer interface emerging from the island-like nuclei. While this phenomenon contributes to increasing filler-polymer interactions, ${ }^{51}$ the resulting interfacial areas further decrease the space charge injection due to their exposure to the amine functionality.

At elevated reaction temperatures, however, the water in the system tends to desorb from the silica surface and enters the solution medium. ${ }^{52}$ In this situation, the condensation of the silane is more likely to happen before its attachment to the silica. This would result in grafting of longer APTES chains to the silica, which leads to a smoother silica surface morphology exhibiting lower nucleation potential. It is also noteworthy that these differences are only observed for the PP-phase crystallization curve, suggesting that the nanoparticles are mostly located in this phase rather than in EOC. This observation is also in-line with the SEM images shown in Figure 7.

\section{CONCLUSIONS}

Successful deposition of APTES on fumed silica nanoparticles is confirmed by TGA, FTIR, and XPS test results. Different modification conditions result in different levels of grafting density as well as different APTES film morphologies. From TSDC data, a substantial shift to higher energy levels and a significant reduction in the intensity are observed for the space charge relaxation peak. These observations, in conjunction with BDS results, suggest that the presence of the amine moiety at the filler-polymer interface induces deep trap states. In this case, the deeply trapped charges hinder further injection of space charges. The space charge injection, however, is not only affected by the amount of deposited silane, but also by its morphology. It is speculated that upon deposition of APTES on silica, an island-like morphology can be formed on the surface at lower modification temperatures when water is present in the system. These "islands" can facilitate nucleation by acting as individual nuclei and inducing transcrystallization at the filler-polymer interface. Moreover, the presence of island-like structures on the silica surface would further contribute to the induction of deep traps at the filler-polymer interface, which results in the reduction of space charge injection.

\section{ASSOCIATED CONTENT}

\section{Supporting Information}

The Supporting Information is available free of charge at https://pubs.acs.org/doi/10.1021/acsapm.0c00349.

The amount of injected and released charges during TSDC measurements for each tested NC (PDF)

\section{AUTHOR INFORMATION}

\section{Corresponding Author}

Wilma Dierkes - Chair of Elastomer Technology and Engineering, Department of Mechanics of Solids, Surfaces \& Systems (MS3), Faculty of Engineering Technology, University of Twente, 7500 Enschede, The Netherlands; Email: w.k.dierkes@utwente.nl

\section{Authors}

Amirhossein Mahtabani - Chair of Elastomer Technology and Engineering, Department of Mechanics of Solids, Surfaces \& Systems (MS3), Faculty of Engineering Technology, University of Twente, 7500 Enschede, The Netherlands; ㅇo이.org/ 0000-0003-2038-012X

Ilkka Rytöluoto - High Voltage Engineering, Tampere University, FI-33014 Tampere, Finland; VTT Technical Research Centre of Finland Ltd., 33101 Tampere, Finland

Rafal Anyszka - Chair of Elastomer Technology and Engineering, Department of Mechanics of Solids, Surfaces \& Systems (MS3), Faculty of Engineering Technology, University of Twente, 7500 Enschede, The Netherlands

Xiaozhen He - Chair of Elastomer Technology and Engineering, Department of Mechanics of Solids, Surfaces \& Systems (MS3), Faculty of Engineering Technology, University of Twente, 7500 Enschede, The Netherlands; 10 orcid.org/0000-0002-90189200

Eetta Saarimäki - VTT Technical Research Centre of Finland Ltd., 33101 Tampere, Finland

Kari Lahti - High Voltage Engineering, Tampere University, FI33014 Tampere, Finland

Mika Paajanen - VTT Technical Research Centre of Finland Ltd., 33101 Tampere, Finland

Anke Blume - Chair of Elastomer Technology and Engineering, Department of Mechanics of Solids, Surfaces \& Systems (MS3), Faculty of Engineering Technology, University of Twente, 7500 Enschede, The Netherlands

Complete contact information is available at:

https://pubs.acs.org/10.1021/acsapm.0c00349

\section{Funding}

This project has received funding from the European Union's Horizon 2020 research and innovation program under grant agreement no. 720858 .

\section{Notes}

The authors declare no competing financial interest. 


\section{ACKNOWLEDGMENTS}

The authors would like to thank the ECIU Researcher Mobility Fund for supporting this research work, Evonik Industries for providing the silica, and Dave Breen and Niels ter Weele for analyzing the SEM images with ImageJ.

\section{REFERENCES}

(1) Ma, D.; Hugener, T. A.; Siegel, R. W.; Christerson, A.; Mårtensson, E.; Önneby, C.; Schadler, L. S. Influence of Nanoparticle Surface Modification on The Electrical Behaviour of Polyethylene Nanocomposites. Nanotechnology 2005, 16, 724.

(2) Huang, X.; Jiang, P.; Yin, Y. Nanoparticle Surface Modification Induced Space Charge Suppression in Linear Low Density Polyethylene. Appl. Phys. Lett. 2009, 95, No. 242905.

(3) Huang, X.; Zheng, Y.; Jiang, P.; Yin, Y. Influence of Nanoparticle Surface Treatment on The Electrical Properties of Cycloaliphatic Epoxy Nanocomposites. IEEE Trans. Dielectr. Electr. Insul. 2010, 17, 635-643.

(4) Montanari, G. C.; Seri, P.; Paajanen, M.; Lahti, K.; Rytöluoto, I.; Ritamäki, M.; Blume, A.; Dierkes, W.; Mahtabani, A.; He, X. In Potentiality of Nanofilled Thermoplastic Insulation for DC Cables and Capacitors, IEEE 2nd International Conference on Dielectrics (ICD); 2018; pp 1-4.

(5) Tian, F.; Yao, J.; Li, P.; Wang, Y.; Wu, M.; Lei, Q. Stepwise Electric Field Induced Charging Current and Its Correlation with Space Charge Formation in LDPE/Zno Nanocomposite. IEEE Trans. Dielectr. Electr. Insul. 2015, 22, 1232-1239.

(6) Zhou, Y.; Hu, J.; Dang, B.; He, J. Titanium Oxide Nanoparticle Increases Shallow Traps to Suppress Space Charge Accumulation in Polypropylene Dielectrics. RSC Adv. 2016, 6, 48720-48727.

(7) Zhou, Y.; He, J.; Hu, J.; Dang, B. Surface-Modified $\mathrm{MgO}$ Nanoparticle Enhances the Mechanical and Direct-Current Electrical Characteristics of Polypropylene/Polyolefin Elastomer Nanodielectrics. J. Appl. Polym. Sci. 2016, 133, No. 42863.

(8) Zhang, L.; Khani, M. M.; Krentz, T. M.; Huang, Y.; Zhou, Y.; Benicewicz, B. C.; Nelson, J. K.; Schadler, L. S. Suppression of Space Charge in Crosslinked Polyethylene Filled with Poly(Stearyl Methacrylate)-Grafted $\mathrm{SiO}_{2}$ Nanoparticles. Appl. Phys. Lett. 2017, 110, No. 132903.

(9) Smith, R. C.; Liang, C.; Landry, M.; Nelson, J. K.; Schadler, L. S. The Mechanisms Leading to the Useful Electrical Properties of Polymer Nanodielectrics. IEEE Trans. Dielectr. Electr. Insul. 2008, 15, 187-196.

(10) Lewis, T. J. Nanometric Dielectrics. IEEE Trans. Dielectr. Electr. Insul. 1994, 1, 812-825.

(11) Fabiani, D.; Montanari, G. C.; Testa, L.; Schifani, R.; Guastavino, F.; Bellucci, F.; Deorsola, F. In Effect of Water Adsorption on the Dielectric Properties of Polymer Nanocomposites, International Symposium on Electrical Insulating Materials (ISEIM 2008); 2008; pp 510-513.

(12) Montanari, G.; Cavallini, A.; Guastavino, F.; Coletti, G.; Schifani, R.; del Casale, M. L.; Camino, G.; Deorsola, F. In Microscopic and Nanoscopic EVA Composite Investigation: Electrical Properties and Effect of Purification Treatment, 17th Annual Meeting of the IEEE Lasers and Electro-Optics Society; 2004; pp 318-321.

(13) Nelson, J. K. Dielectric Polymer Nanocomposites; Springer, 2010. (14) Xiao, Z.; Li, Y.; Ma, D.; Schadler, L. S.; Akpalu, Y. A. Probing the Use of Small-Angle Light Scattering for Characterizing Structure of Titanium Dioxide/Low-Density Polyethylene Nanocomposites. J. Polym. Sci., Part B: Polym. Phys. 2006, 44, 1084-1095.

(15) Brown, D.; Mélé, P.; Marceau, S.; Albérola, N. D. A Molecular Dynamics Study of a Model Nanoparticle Embedded in a Polymer Matrix. Macromolecules 2003, 36, 1395-1406.

(16) Sternstein, S. S.; Zhu, A.-J. Reinforcement Mechanism of Nanofilled Polymer Melts As Elucidated by Nonlinear Viscoelastic Behavior. Macromolecules 2002, 35, 7262-7273.

(17) Mahtabani, A.; Alimardani, M.; Razzaghi-Kashani, M. Further Evidence of Filler-Filler Mechanical Engagement in Rubber
Compounds Filled with Silica Treated by Long-Chain Silane. Rubber Chem. Technol. 2017, 90, 508-520.

(18) He, X.; Rytöluoto, I.; Anyszka, R.; Mahtabani, A.; Saarimäki, E.; Lahti, K.; Paajanen, M.; Dierkes, W.; Blume, A. Surface Modification of Fumed Silica by Plasma Polymerization of Acetylene for PP/POE Blends Dielectric Nanocomposites. Polymers 2019, 11, No. 1957.

(19) Kasperovich, V.; Wong, K.; Tikhonov, G.; Kresin, V. V. Electron Capture by the Image Charge of a Metal Nanoparticle. Phys. Rev. Lett. 2000, 85, No. 2729.

(20) Khalil, M. S. The Role of $\mathrm{BaTiO}_{3}$ in Modifying the DC Breakdown Strength of LDPE. IEEE Trans. Dielectr. Electr. Insul. 2000, 7, 261-268.

(21) Alimardani, M.; Razzaghi-Kashani, M.; Karimi, R.; Mahtabani, A. Contribution of Mechanical Engagement and Energetic Interaction in Reinforcement of SBR-Silane Treated Silica Composites. Rubber Chem. Technol. 2016, 89, 292-305.

(22) Natarajan, B.; Li, Y.; Deng, H.; Brinson, L. C.; Schadler, L. S. Effect of Interfacial Energetics on Dispersion and Glass Transition Temperature in Polymer Nanocomposites. Macromolecules 2013, 46, 2833-2841.

(23) Mathabani, A.; Rytöluoto, I.; He, X.; Saarimäki, E.; Lahti, K.; Paajanen, M.; Anyszka, R.; Dierkes, W.; Blume, A. In Solution Modified Fumed Silica and Its Effect on Charge Trapping Behavior of PP/POE/ Silica Nanodielectrics, Proceedings of the Nordic Insulation Symposium; 2019; pp 129-133.

(24) He, X.; Mahtabani, A.; Rytöluoto, I.; Saarimäki, E.; Lahti, K.; Paajanen, M.; Anyszka, R.; Dierkes, W.; Blume, A. In Surface Modification of Fumed Silica by Dry Silanization for PP-based Dielectric Nanocomposites, 2nd International Conference on Electrical Materials and Power Equipment (ICEMPE); 2019; pp 254-259.

(25) Siddabattuni, S.; Schuman, T. P.; Dogan, F. Dielectric Properties of Polymer-Particle Nanocomposites Influenced by Electronic Nature of Filler Surfaces. ACS Appl. Mater. Interfaces 2013, 5, 1917-1927.

(26) Lau, K. Y.; Vaughan, A. S.; Chen, G.; Hosier, I. L. In Space Charge Dynamics in Silica-Based Polyethylene Nanocomposites, Proceedings of IEEE International Conference on Solid Dielectrics (ICSD); 2013; pp 880-883.

(27) Yamano, Y.; Endoh, H. Increase in Breakdown Strength of PE Film by Additives of Azocompounds. IEEE Trans. Dielectr. Electr. Insul. 1998, 5, 270-275.

(28) Huang, Y.; Wu, K.; Bell, M.; Oakes, A.; Ratcliff, T.; Lanzillo, N. A.; Breneman, C.; Benicewicz, B. C.; Schadler, L. S. The Effects of Nanoparticles and Organic Additives with Controlled Dispersion on Dielectric Properties of Polymers: Charge Trapping and Impact Excitation. J. Appl. Phys. 2016, 120, No. 055102.

(29) Huang, Y.; Schadler, L. S. On the Nature of High Field Charge Transport in Reinforced Silicone Dielectrics: Experiment and Simulation. J. Appl. Phys. 2016, 120, No. 055101.

(30) Zhang, C.; Mizutani, T.; Kaneko, K.; Mori, T.; Ishioka, M. Space Charge Behaviors of Low-Density Polyethylene Blended with Polypropylene Copolymer. Polymer 2002, 43, 2261-2266.

(31) Wang, X.; Lv, Z.; Wu, K.; Chen, X.; Tu, D.; Dissado, L. A. Study of the Factors That Suppress Space Charge Accumulation in LDPE Nanocomposites. IEEE Trans. Dielectr. Electr. Insul. 2014, 21, $1670-1679$.

(32) Xu, X.; Li, B.; Lu, H.; Zhang, Z.; Wang, H. The Effect of the Interface Structure of Different Surface-Modified Nano- $\mathrm{SiO}_{2}$ on the Mechanical Properties of Nylon 66 Composites. J. Appl. Polym. Sci. 2008, 107, 2007-2014.

(33) Fukuyama, Y.; Kawai, T.; Kuroda, S.-i.; Toyonaga, M.; Taniike, T.; Terano, M. The Effect of the Addition of Polypropylene Grafted $\mathrm{SiO}_{2}$ Nanoparticle on the Crystallization Behavior of Isotactic Polypropylene. J. Therm. Anal. Calorim. 2013, 113, 1511-1519.

(34) Dang, B.; He, J.; Hu, J.; Zhou, Y. Large Improvement in Trap Level and Space Charge Distribution of Polypropylene by Enhancing the Crystalline - Amorphous Interface Effect in Blends. Polym. Int. 2016, 65, 371-379. 
(35) Chi, X.; Cheng, L.; Liu, W.; Zhang, X.; Li, S. Characterization of Polypropylene Modified by Blending Elastomer and Nano-Silica. Materials 2018, 11, No. 1321.

(36) Pasternack, R. M.; Rivillon Amy, S.; Chabal, Y. J. Attachment of 3-(Aminopropyl)triethoxysilane on Silicon Oxide Surfaces: Dependence on Solution Temperature. Langmuir 2008, 24, 12963-12971.

(37) Qiao, B.; Wang, T.-J.; Gao, H.; Jin, Y. High Density Silanization of Nano-Silica Particles Using $\gamma$-aminopropyltriethoxysilane (APTES). Appl. Surf. Sci. 2015, 351, 646-654.

(38) Arganda-Carreras, I.; Kaynig, V.; Rueden, C.; Eliceiri, K. W.; Schindelin, J.; Cardona, A.; Seung, H. S. Trainable Weka Segmentation: a Machine Learning Tool for Microscopy Pixel Classification. Bioinformatics 2017, 33, 2424-2426.

(39) Blume, A.; Jin, J.; Mahtabani, A.; He, X.; Kim, S.; Andrzejewska, Z. In New Structure Proposal for Silane Modified Silica, Proceedings from International Rubber Conference, London; 2019.

(40) Vansant, E. F.; Van Der Voort, P.; Vrancken, K. C. Characterization and Chemical Modification of the Silica Surface; Elsevier, 1995.

(41) Zhong, G. J.; Li, Z. M. Injection Molding-Induced Morphology of Thermoplastic Polymer Blends. Polym. Eng. Sci. 2005, 45, 16551665.

(42) Ying, J.; Xie, X.; Peng, S.; Zhou, H.; Li, D. Morphology and Rheology of $\mathrm{PP} / \mathrm{POE}$ Blends in High Shear Stress Field. J. Thermoplast. Compos. Mater. 2018, 31, 1263-1280.

(43) Andritsch, T.; Vaughan, A.; Stevens, G. C. Novel Insulation Materials for High Voltage Cable Systems. IEEE Electr. Insul. Mag. 2017, 33, 27-33.

(44) Nelson, J. K.; Fothergill, J. C. Internal Charge Behaviour of Nanocomposites. Nanotechnology 2004, 15, 586.

(45) Kao, K. C. Dielectric Phenomena in Solids; Elsevier, 2004.

(46) Tian, F.; Bu, W.; Shi, L.; Yang, C.; Wang, Y.; Lei, Q. Theory of Modified Thermally Stimulated Current and Direct Determination of Trap Level Distribution. J. Electrostat. 2011, 69, 7-10.

(47) Abbasi-Shirsavar, M.; Baghani, M.; Taghavimehr, M.; Golzar, M.; Nikzad, M.; Ansari, M.; George, D. An Experimental-Numerical Study on Shape Memory Behavior of PU/PCL/ZnO Ternary Blend. J. Intell. Mater. Syst. Struct. 2019, 30, 116-126.

(48) Rychkov, A. A.; Trifonov, S. A.; Kuznetsov, A. E.; Sosnov, E. A.; Rychkov, D. A.; Malygin, A. A. Influence of Chemical Modification of The Surface of Low-Density Polyethylene on its Electret Properties. Russ. J. Appl. Chem. 2007, 80, 461-465.

(49) Lin, C. W.; Ding, S. Y.; Hwang, Y. W. Interfacial Crystallization of Isotactic Polypropylene Molded Against the Copper Surface with Various Surface Roughnesses Prepared by an Electrochemical Process. J. Mater. Sci. 2001, 36, 4943-4948.

(50) Abdou, J. P.; Reynolds, K. J.; Pfau, M. R.; van Staden, J.; Braggin, G. A.; Tajaddod, N.; Minus, M.; Reguero, V.; Vilatela, J. J.; Zhang, S. Interfacial Crystallization of Isotactic Polypropylene Surrounding Macroscopic Carbon Nanotube and Graphene Fibers. Polymer 2016, 91, 136-145.

(51) Ning, N.; Fu, S.; Zhang, W.; Chen, F.; Wang, K.; Deng, H.; Zhang, Q.; Fu, Q. Realizing the Enhancement of Interfacial Interaction in Semicrystalline Polymer/Filler Composites via Interfacial Crystallization. Prog. Polym. Sci. 2012, 37, 1425-1455.

(52) Howarter, J. A.; Youngblood, J. P. Optimization of Silica Silanization by 3-Aminopropyltriethoxysilane. Langmuir 2006, 22, 11142-11147.

\section{NOTE ADDED AFTER ASAP PUBLICATION}

This article originally published with an incomplete title. The correct title reposted July 31, 2020. 